\title{
The effectiveness of US mitigation and monitoring practices for the threatened Valley elderberry longhorn beetle
}

\author{
Marcel Holyoak · Theresa S. Talley • \\ Sara E. Hogle
}

Received: 9 October 2008/Accepted: 7 April 2009/Published online: 23 April 2009

(c) The Author(s) 2009. This article is published with open access at Springerlink.com

\begin{abstract}
Habitat mitigation frequently leads to planting of new habitat, assuming that it can replace lost natural habitat. Yet this practice has rarely been examined in detail. In the USA habitat mitigation is frequently allowed under the US Endangered Species Act, providing monitoring reports which represent a potentially valuable data source for imperiled species. We used publicly available reports for the US threatened Valley elderberry longhorn beetle (Desmocerus californicus dimorphus) to assess record keeping practices used by US Fish and Wildlife Service (FWS), and the utility of such analyses for improving conservation. A large portion of mitigation reports known to exist were missing from FWS files, indicating problems with data management, and a loss of important information. Transplanted brought mature beetle host plants and beetles to sites, promoting beetle colonization. Conversely, few sites with seedlings were colonized. Results indicate a need for improved data management by FWS and longer term monitoring.
\end{abstract}

Keywords Desmocerus californicus dimorphus . Habitat conservation plan · Habitat offset - Restoration . Riparian · Endangered species

\section{Introduction}

In many parts of the world, for imperiled species habitat loss that is legal but unavoidable and does not directly promote population extinction can be mitigated (compensated) for

M. Holyoak $(\bowtie) \cdot$ T. S. Talley · S. E. Hogle

Department of Environmental Science and Policy, University of California, One Shields Avenue, Davis, CA 95616, USA

e-mail: maholyoak@ucdavis.edu either by creating new habitat or enhancing existing habitat. The success of this process relies on our ability to effectively enhance or create new habitat that will be used by the target species. New (2009) suggests that habitat offsets might represent an effect on conservation which is more placebo than clearly beneficial. The potential problems with offsets are well illustrated by studies of the effectiveness of mitigation conducted through habitat conservation plans (HCPs) promulgated by the US Endangered Species Act (ESA; the next section gives more background on this process). Previous studies and commentaries have raised several concerns over this process, including the following: (1) smallscale projects may fragment habitat (Noss et al. 1997, p. 34); (2) impacts may not be fully offset by mitigation because of uncertainty, failure, or creation of low quality habitat (Allen 1994; Smallwood et al. 1999); (3) biological information and scientific review may be under-utilized in planning and executing mitigation (Kareiva et al. 1999); and (4) there is little public input into decision-making, despite its potential to enhance mitigation (Kareiva et al. 1999 and references therein). We assessed the utility of analyses of publically available mitigation monitoring reports (kept by US Fish and Wildlife Service; "FWS") for improving the conservation and mitigation of a rare insect species. Mitigation reports were also used to evaluate the completeness of record keeping about mitigation by FWS, which reflects this regulatory agency's ability to use such information to improve mitigation practices. We investigated mitigation for one threatened form, a subspecies of beetle about which we have specialist knowledge, but since we evaluated general procedures, many of our findings are somewhat general.

The most relevant previous study is where a large team evaluated in detail 43 HCPs representing 64 species (97 species-plan combinations) and 208 HCPs in less detail (Kareiva et al. 1999; Harding et al. 2001; Watchman et al. 
2001). A variety of important problems were identified: (1) HCPs infrequently identified the number of individuals expected to be taken; (2) cumulative, region-wide impacts from multiple projects were rarely considered; (3) some HCPs did not consider known impacts; (4) uncertainty in mitigation success was rarely addressed; (5) mitigation success was frequently not monitored and was considered adequate for only $16 \%$ of plans; and (6) adaptive management was rarely used to correct undesirable results of using HCPs prepared with little data (see also Wilhere 2002). Subsequently, improved monitoring and adaptive management were adopted by FWS and NOAA in June 2000 (Watchman et al. 2001). FWS (2007) also responded that take can be assessed through habitat loss rather than number of individuals taken, that cumulative impacts were considered elsewhere in the HCP consultation process, and that both the information in HCPs and the monitoring required are commensurate with expected take. Nonetheless FWS (2007) suggested they would establish measurable biological goals and objectives, incorporate adaptive management, and improve monitoring and public participation in the process. These problems with mitigation monitoring and assessment are not unique to mitigation for imperiled species, since a US National Research Council report (Committee on Mitigating Wetland Losses 2001) reached broadly similar conclusions.

Rather than conducting a broad survey of many species we focused on one imperiled species using an alternative source of information, reports on mitigation and equivalent ESA Sect. 7 consultations (see the next section), available through FWS and California Academy of Sciences. Mitigation reports give quantitative information indicating the success or failure of mitigation activities, and represent a valuable source of information about listed species, which are difficult to study because of species' rarity and protected status. Mitigation, like restoration, can be viewed as a natural experiment for testing hypotheses about site colonization and development.

An ideal species for this purpose is the US threatened Valley elderberry longhorn beetle ("VELB"), Desmocerus californicus dimorphus Fisher (Coleoptera: Cerambycidae), which is endemic to California's Central Valley (Linsley and Chemsak 1972; FWS 1980, 1984; Barr 1991). The primary reason for imperilment is habitat loss; since 1,800 over $90 \%$ of riparian forests in California have been lost and heavily fragmented by urbanization and agriculture (Smith 1980; Katibah et al. 1984). The species has been the target of a large number of mitigation projects and restoration efforts, in part because of the overlap between its populations and both urban and agricultural development. Habitat for the species consists of blue elderberry (Sambucus mexicana C. Presl: Caprifoliaceae), a common shrub in riparian and similar habitats. Mitigation consists of planting elderberry seedlings and transplanting mature shrubs from impacted sites to new mitigation sites (for further requirements see "The study system" in the "Materials and Methods" section); sites are areas from $<1$ ha to thousands of hectares, with anything from a few planted elderberry to over 4,000 plants.

We had four aims. (1) We evaluated the completeness of both mitigation reporting and the information available to FWS. This is important since the monitoring reports typically represent FWS's only information to evaluate the mitigation process. (2) We documented the extent of mitigation efforts, which is useful for assessing cumulative impacts. Despite the large proportion of reports which we expected to be present but which were missing from records, we still located over 90 reports containing extensive information (Tables 1, 2), which enabled us to ask two further questions: (3) We quantified mitigation success by estimating how frequently the beetle colonized mitigation sites and survival of the beetle's host plant, elderberry. (4) We tested the influence of site age and horticultural practices on host plant survival and beetle colonization of sites. In our discussion we also give recommendations as to how mitigation reporting and monitoring practices might be improved.

\section{Materials and methods}

Below we describe the legal background which is required to understand the mitigation process performed under the auspices of the US Endangered Species Act (ESA). We then give the information required to understand the species under consideration and the habitat in which it lives. The data used and methods for extracting data from these mitigation reports is then reported (to tackle aims 3-4 above), followed by our methods of estimating the completeness of reporting of mitigation efforts (aims 1-2).

Legal background

Before 1982 the US ESA was frequently regarded by private landowners as overly restrictive because of its absolute prohibition on the "take" of threatened and endangered animals, and their habitat (Bingham and Noon 1997; Kareiva et al. 1999). In this context, take means to "harass, harm, pursue, hunt, shoot, wound, kill, trap, capture, or collect, or attempt to engage in any such conduct" (ESA 1973), and harm includes damage to habitat (US Fish and Wildlife Service, "FWS" 1981). Consequently, in 1982 congress modified the ESA to allow incidental takings if a satisfactory HCP was prepared and approved by FWS (or equivalently National Oceanic and Atmospheric Administration, NOAA, for marine and anadromous species). HCPs make the ESA more flexible and were intended 
Table 1 Characteristics recorded from FWS mitigation reports

\begin{tabular}{|c|c|c|}
\hline Characteristics & Type of values & $\%$ \\
\hline \multicolumn{3}{|l|}{ Site characteristics } \\
\hline Irrigation type & Name & 74 \\
\hline \multicolumn{3}{|l|}{ Elderberry characteristics } \\
\hline Number planted & Number & 95 \\
\hline Planting type & Transplant, seedling, natural recruit & 97 \\
\hline Year planted & Year & NA \\
\hline Height category $(\mathrm{m})$ & $0-1,1-2,2-3,>3$ & 18 \\
\hline Mean height (m) & Given in $\mathrm{m}$ or approximated in $\mathrm{m}$ from height category & 26 \\
\hline Number of main stems in diameter class & $<2.5 \mathrm{~cm},>2.5 \mathrm{~cm}, 2-7 \mathrm{~cm}, 7-12 \mathrm{~cm}, 12-20 \mathrm{~cm},>20 \mathrm{~cm}$ & 11 \\
\hline Mean stem diameter $(\mathrm{cm})$ & Size in $\mathrm{cm}$, given or approximated from diameter classes & 8 \\
\hline Condition of shrub & Excellent/vigorous $=4$, good $=3$, fair $=2$, poor $=1$, dead $=0$ & 59 \\
\hline Mean condition & Mean score, given or approximated from condition classes & 49 \\
\hline$\%$ survival & $\%$, given or calculated from condition classes & 87 \\
\hline \multicolumn{3}{|l|}{ Beetle data } \\
\hline Number of exit holes & Number of holes: new, old, 1-year-old, partly closed, or closed & 81 \\
\hline Were holes present before transplanting? & Yes or no & 81 \\
\hline$\%$ of shrubs with beetles & Percentage & 81 \\
\hline
\end{tabular}

$\%$ is the percent of 174 plantings for which data were obtained. NA not applicable based on the presence of this information being a part of the site selection criteria

Table 2 Mitigation efforts by counties or county groups during 1989-1999

\begin{tabular}{|c|c|c|c|c|c|c|c|c|c|c|c|}
\hline \multirow[t]{3}{*}{ County } & \multicolumn{4}{|c|}{ Seedlings } & \multicolumn{4}{|c|}{ Transplants } & \multirow{2}{*}{\multicolumn{3}{|c|}{ Human population }} \\
\hline & \multicolumn{2}{|c|}{ Plantings } & \multicolumn{2}{|l|}{ Shrubs } & \multicolumn{2}{|c|}{ Plantings } & \multicolumn{2}{|l|}{ Shrubs } & & & \\
\hline & $N$ & $\%$ & $N$ & $\%$ & $N$ & $\%$ & $N$ & $\%$ & Population $^{\mathrm{a}}$ & Growth $(\%)^{\mathrm{b}}$ & Density $^{\mathrm{c}}$ \\
\hline Butte & 5 & 5.7 & 176 & 1.62 & 1 & 2.9 & 1 & 0.1 & 203,171 & 11.6 & 123.90 \\
\hline Calaveras & 2 & 2.3 & 204 & 1.9 & 2 & 5.9 & 66 & 6.1 & 40,554 & 26.7 & 39.80 \\
\hline Fresno \& Madera & 4 & 4.6 & 1,420 & 13.1 & 1 & 2.9 & 17 & 1.6 & 922,516 & 22.5 & 113.90 \\
\hline Glenn \& Colusa & 7 & 8.0 & 744 & 6.9 & 3 & 8.8 & 127 & 11.8 & 45,257 & 10.4 & 18.4 \\
\hline Placer & 5 & 5.7 & 1,454 & 13.4 & 7 & 20.6 & 458 & 42.6 & 248,399 & 43.8 & 176.9 \\
\hline Sacramento & 11 & 12.6 & 2,217 & 20.4 & 8 & 23.5 & 132 & 12.3 & $1,223,499$ & 14.7 & $1,267.0$ \\
\hline San Joaquin & 0 & 0.0 & 0 & 0.0 & 1 & 2.9 & 24 & 2.2 & 563,598 & 17.3 & 402.8 \\
\hline Solano & 3 & 3.4 & 98 & 0.9 & 1 & 2.9 & 4 & 0.4 & 394,542 & 16.2 & 475.8 \\
\hline Stanislaus & 1 & 1.1 & 15 & 0.1 & 1 & 2.9 & 2 & 0.2 & 446,997 & 20.6 & 299.2 \\
\hline Tehama & 19 & 21.8 & 1,326 & 12.2 & 6 & 17.6 & 221 & 20.6 & 56,039 & 12.9 & 19.0 \\
\hline Yolo & 30 & 34.5 & 3,206 & 29.5 & 3 & 8.8 & 22 & 2.0 & 168,660 & 19.40 & 166.5 \\
\hline Sum & 87 & 100 & 10,860 & 100 & 34 & 100 & 1,074 & 100 & NA & NA & NA \\
\hline
\end{tabular}

There were no mitigation reports for counties not included in the table. For grouped counties the total across counties is given (divide by the number of counties to make this comparable to single counties). Human population data came from US Census Bureau (2005). NA not applicable

${ }^{\text {a }}$ In year 2000

b From 1990 to 2000

${ }^{\mathrm{c}}$ In persons per square mile

to promote regional conservation planning (Bonnie 1999; Smallwood et al. 1999). This flexibility is achieved by ESA Sect. 10(a), which authorizes FWS and NOAA to issue permits to allow legal activities that might lead to incidental taking of a threatened or endangered species in exchange for the acting party undertaking mitigation through a HCP or acquiring land for conservation of the impacted species. To proceed, take of a species must be incidental to an otherwise legal activity, it must not lead to increased risk of extinction of the protected species, and 
the acting party must minimize and mitigate habitat loss to "the maximum extent practicable" (FWS and National Marine Fisheries Service 1998).

While ESA Sect. 10(a)(1)(B) applies to individuals and organizations without a Federal nexus, analogous activities are undertaken by Federal agencies in interagency consultations through ESA Sect. 7. Unlike HCP's performed under Sect. 10(a)(1)(B), Sect. 7 consultations require the acting agency to minimize incidental take (there is no "to the maximum extent practicable" limitation), and there is no "no surprises" clause giving regulated certainty against the need for further action should mitigation fail (e.g., due to fire or flooding) (FWS and National Marine Fisheries Service 1998). However, mitigation is comparable for federal agencies and nonfederal parties.

The study system and mitigation procedures

The VELB completes all but the dispersal phase of its life cycle on blue elderberry (Sambucus mexicana C. Presl: Caprifoliaceae). Its larvae develop inside elderberry stems of $\geq 2.5 \mathrm{~cm}$ diameter for 1-2 years (Barr 1991). Adults emerge from the stems in spring, leaving distinctive emergence holes $(\sim 1 \mathrm{~cm}$ in diameter $)$ that are reliable indicators of previous presence (Barr 1991). These holes are an important source of information about beetle populations, which are labor intensive to census (Talley et al. 2006). Naturally VELB occur in metapopulations, which occupy watersheds and consist of a number of extinctionprone local populations of unknown size, and between-site dispersal is important for recolonization of sites (Collinge et al. 2001; Talley 2007). Continued uncertainty about how to manage the beetle has led FWS to revise the conservation guidelines for its management three times since 1988 (FWS 1988, 1994, 1996, 1999). Uncertainties include how to deal with high turnover of site occupancy by the beetle (Collinge et al. 2001), predatory invasive Argentine ants (Linepithema humile) (Huxel 2000), and a perceived low success rate of mitigation. In each revision FWS increased the amount of elderberry needing to be planted to replace each natural elderberry impacted, thereby increasing the cost of mitigation and concern among public agencies and private companies. The VELB's range is also centered on Sacramento, California, a city of 445,000 (in 2003) and growing at over 3\% per year (based on 2000-2003 data; US Census Bureau 2005), leading to a broad overlap between its occurrence and urbanization. Nonetheless, since 1980 the number of VELB records has increased from ten to over 190; although, it is hard to interpret these figures because many records represent repeated recording of the same populations that were in the original records, and overall population trends are unclear (Talley et al. 2006).

Mitigation for the VELB consists of planting elderberry and associated native plant species, transplanting elderberry shrubs that would be impacted by development, and protecting mitigation sites in perpetuity (FWS 1999). We use the term, elderberry "seedlings" to include plants propagated from seeds and from cuttings taken from shrubs in the impacted area. Transplants are shrubs with a basal stem diameter of at least $2.5 \mathrm{~cm}$ that are pruned back to the main stem and moved from the site of impact to the mitigation site. Shrubs are watered to enhance survival, and a minimum of $60-80 \%$ survival is required during the first 510 years (depending on the year of initiation and hence the guidelines used). Additional seedlings must be planted to compensate for survival lower than the required amount. Sites are monitored for ten consecutive years, or optionally for seven times over a 15 year period for sites planted after 1994 (FWS 1994). Monitoring consists of censusing beetles, beetle exit holes, elderberry number and condition, and recording a variety of general site conditions. After 1993, native plants were required to be planted and at least $60 \%$ survival of these was required after 10 years. FWS requires that a qualified biologist prepares a written report, which presents the analyzed data from the project monitoring. The reports should be submitted to FWS, California Department of Fish and Game (CaDFG) and the library of the California Academy of Sciences (CAS) in each year in which monitoring is required.

Factors thought to be important for success of VELB mitigation include the age, size and nutrient composition of elderberry (Barr 1991; Talley et al. 2007), the direct and indirect effects of predator species (Huxel 2000), and habitat patch size, distribution and location (Collinge et al. 2001; Talley et al. 2007). Direct evaluation of VELB mitigation sites has been conducted by Holyoak and KochMunz (2008) and Koch-Munz and Holyoak (2008), but is limited to a survey of only 30 sites. These direct evaluations show an influence of soil factors on elderberry growth (Koch-Munz and Holyoak 2008), and of plant (elderberry) stress and site size and age on beetle colonization (Holyoak and Koch-Munz 2008).

\section{Mitigation reports}

Staff at the Sacramento (California) FWS field office used a database to locate VELB mitigation files by file number in May to August 2002. Files contained an approved mitigation proposal and any mitigation reports submitted to and filed at FWS. Many files contained mitigation proposals but no mitigation reports (numbers of such files were not tracked by us). In such cases it is unclear whether 
projects did not proceed or whether reports were not filed. We therefore omitted such cases from all analyses, while recognizing that further work is required to assess such cases. Data fields in Table 1 were extracted from mitigation reports and files were searched for additional information about site circumstances that might relate to elderberry, beetle or site condition. Sites often received multiple plantings in different years-a planting was a number of either seedlings planted or transplanted mature elderberry plants, and transplants and seedlings were considered as separate plantings. FWS records provided 90 reports, and 85 of these, from 60 sites, contained the report from the year of planting and could be used in analyses. Nine of these reports (from four sites) were obtained directly from companies responsible for conducting the mitigation or monitoring rather than from FWS records. We also put considerable effort into attempting to gain access to the VELB mitigation reports submitted to CaDFG but staff were either unable to tell us where reports were retained or staff did not return telephone calls or respond to email messages. We obtained 24 reports from 16 sites at the CAS library that were within the dates specified below and used these only in analyses of the completeness of mitigation reporting and in estimating the number of reports missing from FWS files. CAS has not systematically kept mitigation reports sent to their library and has a haphazard collection of reports relative to the larger collection at FWS.

Analyses of the completeness of mitigation records and extent of mitigation efforts

In our analyses we omitted data from the years 2000-2002. This reflects that some reports in this period may not yet have been filed by FWS although they were completed by mitigators and received by FWS. The choice of years to omit was based on advice from FWS staff; since FWS practices have not changed we do not consider the choice of years as representing a source of bias. Based on Conservation Guidelines (FWS 1988, 1994, 1996) we expected to find annual reports for projects started in the 10 years prior to 1996. After 1996, mitigation reporting conditions were changed (FWS 1996, 1999), but reports were still required from years 1, 2 and 3. Hence, annual reports were expected for all sites up to and including 1999. This expectation and the presence of a report with a planting date allowed us to assess the expected and observed number of reports that were missing prior to 2000 for each calendar year. We recognize that this procedure may under-record the number of missing reports because for a site no reports may have been available and therefore the site may have been entirely omitted.

\section{Results}

Completeness of data

There were 60 sites with reports that contained a year of planting, providing evidence of when sites were planted; this included a few projects where a single report covered multiple sites (a site was the unit of replication). Figure 1a shows the number of mitigation reports expected (based on a combination of FWS and CAS data) and discovered at FWS for sites of different ages. Only $36 \%$ of reports were on average filed, suggesting that reports were either lost or not submitted to FWS. There was also a decline in the number of expected reports with site age (Fig. 1a), indicating a recent increase in mitigation reporting (and presumably planting). Note that FWS data keeping practices have not changed substantially to cause this trend. Some $62 \%$ ( 15 of 24) of the reports present at CAS were missing from the FWS files (binomial distribution 95\% confidence limits: $41-81 \%$ ). The observed missing proportion of $64.4 \%$ falls well within this range and we estimate that between $13 \%(64-41 \%)$ and all of the missing reports represent reports that were filed to FWS and since been lost; at least they were unavailable to FWS service staff between May and August 2002. For the CAS library, 89\%
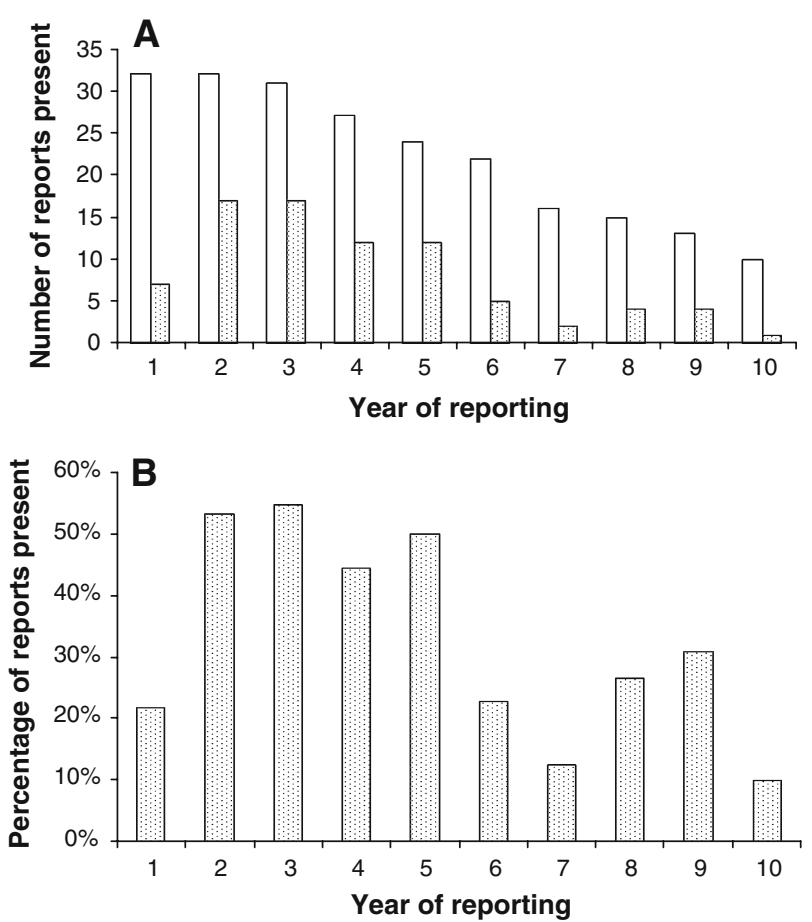

Fig. 1 a Numbers of mitigation reports expected to be filed based on the presence of a report from a site at FWS or CAS (unfilled bars), and numbers of observed reports at FWS (stippled bars). b The percentage of expected reports present at FWS for sites of different ages 
of the expected reports were missing, and staff informed us that there was not a systematic attempt to keep them.

\section{Extent of mitigation efforts}

FWS files indicated that a mean of 2.5 mitigation sites per year were planted with seedlings or transplants between 1989 and 1999. An average of 7.9 plantings per year (range, 1-17 plantings) were made using seedlings within these sites, including replantings (Table 2). Additional plantings in already established sites accounted for $64 \%$ of all plantings and included replacement of dead seedlings and new planting efforts. There were 3.1 plantings per year (range 1-12 plantings) using transplants. The mean number of plants per planting was 124.8 for seedlings, and 31.6 for transplants. Therefore, the total number of elderberry shrubs planted over all sites was 987 seedlings per year and 98 transplants per year. On average $9.9 \%$ of plants were transplants rather than seedlings.
It should be stressed that although there were a large proportion of expected reports that were missing from FWS files, there were still 90 reports in FWS files that were usable for analyses, and large numbers of elderberry bushes that were monitored. The proportion of reports with usable data depended on the variable of interest (Table 1).

\section{Elderberry survival}

An important question for improving mitigation practices is to understand the relative value of transplanted host plant shrubs versus those planted as seedlings. Survival of both seedlings and transplants was highly variable and declined with time since planting (Fig. 2; Table 3). We estimated that $72-75 \%$ of seedlings or transplants survived planting and up to, but not including, the first year of monitoring. There was not a significant difference between seedlings and transplants in these rates (Table 3). By 7 years after planting only $57-64 \%$ of transplants were alive compared
Fig. 2 Predicted survival of seedlings and transplants based on logistic regression analyses in Table 3. Values are backtransformed from analyses with 1 year per site

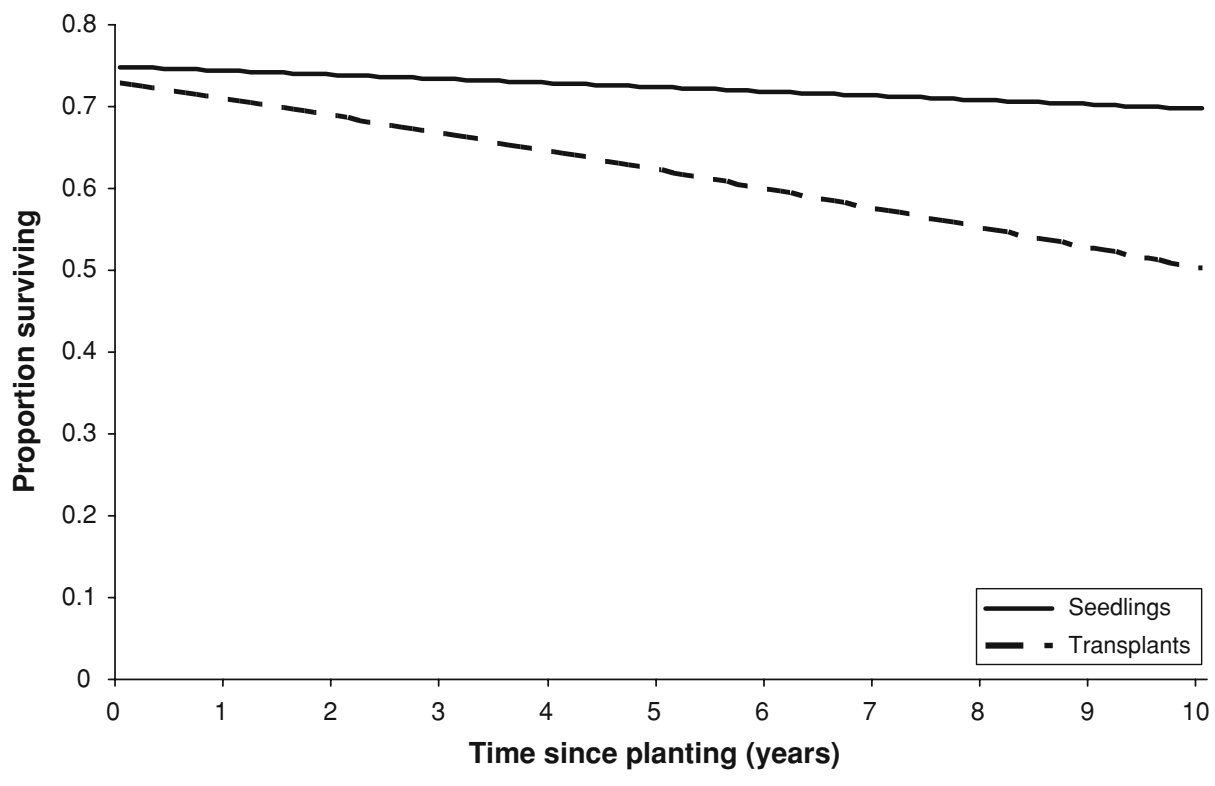

Table 3 Results of logistic regression of cumulative proportion of shrubs that died against number of years since planting

\begin{tabular}{lrllrllll}
\hline & Intercept (SE) & Slope (SE) & $N$ & Chi-squared & $P$ value & Goodness-of-fit & Year-0 survival & Year-7 survival \\
\hline Seedlings, 1 year/site & $-1.091(0.026)$ & $0.130(0.009)$ & 16,513 & 225.5 & $<0.001$ & 0.015 & 0.749 & 0.713 \\
Seedlings, all years/site & $-1.060(0.021)$ & $0.176(0.008)$ & 28,279 & 515.1 & $<0.001$ & 0.019 & 0.743 & 0.714 \\
Transplants, 1 year/site & $-0.982(0.098)$ & $0.411(0.049)$ & 937 & 92.2 & $<0.001$ & 0.098 & 0.728 & 0.574 \\
Transplants, all years/site & $-1.094(0.074)$ & $0.424(0.027)$ & 2,644 & 285.6 & $<0.001$ & 0.105 & 0.749 & 0.641 \\
\hline
\end{tabular}

The proportion dead $(p)$ was $\ln (p /(1-p))$ transformed. Positive slopes indicate death of plants. Chi-squared values have one degree of freedom. $N$ is the number of shrubs in the analysis. Goodness-of-fit was calculated using a statistic from Darlington (1990), that is equivalent to $R^{2}$ in its interpretation. Values were back-transformed to calculate the proportions of shrubs surviving after 0 and 7 years of growth. Analyses with all years per site use non-independent data (breaking an assumption of logistic regression), whereas analyses with 1 year per site use only a fraction of the available data (but the data are independent and no statistical assumptions are broken) 
to $71 \%$ of seedlings. For plants of at least 1 year old, the average annual mortality rate for seedlings was $0.4-0.5 \%$ per year, compared to $1.5-2.2 \%$ dying per year for transplants. Importantly, although the regressions in Table 3 were significant (at $P<0.001$ ) the analyses accounted for only $<2 \%$ of variation in proportion alive in seedlings and $\sim 10 \%$ in transplants.

A logistic model showed that site identity accounted for $25 \%$ of the variance in the proportion of the seedlings alive $\left(\chi_{36}^{2}=4,010, P<0.001\right.$; sample size was too small to analyze transplants). The proportion of shrubs alive following planting mortality at different sites varied from 22 to $100 \%$ (for sites with $>30$ seedlings only, mean proportion alive $=69 \%$ from this analysis). The large amount of variation in plant survival rates among sites indicates that the choice of site can have large effects on our ability to establish elderberry at different sites.

Of direct relevance to horticultural practices, the proportion of shrubs surviving (intercepts in a logistic model with year of planting as a covariate; overall $\chi_{4}^{2}=1,740$ for irrigation, $P<0.001)$ was highest for bubbler irrigation (92\%), followed by hand and drip irrigation (77 and $76 \%$ survival), then no specified type of irrigation (51\%) and sprinkler $(48 \%)$ had lowest survival $(P<0.05$ or lower for all differences; overall $9.5 \%$ of variance was accounted for).

\section{Other elderberry characteristics}

These are elderberry characteristics which are required by FWS to be measured, but for which there is no clear relationship to beetle populations. Often these variables are correlates of a healthy mitigation site (e.g., vigorously growing shrubs), or are putatively relevant to the beetle. Elderberry height data were available from only 16 sites. Both plant sizes and growth rates were highly heterogeneous both within and across sites, and sample sizes were not sufficient to permit meaningful statistical analyses. One year after planting, average seedlings were $0.54 \mathrm{~m}$ tall ( $\mathrm{SD}=0.20, n=6$ sites) and transplants were $1.28 \mathrm{~m}$ tall ( $\mathrm{SD}=0.82, n=8$ sites). Seedlings grew in height by a mean of $0.20 \mathrm{~m}$ per year $(\mathrm{SE}=0.07)$, whereas, transplants grew by $0.41 \mathrm{~m}$ per year $(\mathrm{SE}=0.24)$. However, this difference was not statistically significant $(P>0.05$ in a $t$ test). Inconsistency in reporting hindered these analyses. Absence of measurements, new plantings being averaged together with original plantings (mixing plant age) and data being reported as \% growth without giving absolute sizes were frequently encountered problems. Data on elderberry main stem size was only collected from nine sites, which was insufficient for statistical analysis, and a growth calculation was only possible for one site.
Elderberry condition did not change significantly with site age. Mean condition was positively related to seedling survival rates (linear regression $t=2.74, P<0.02$, $R_{\mathrm{adj}}^{2}=0.24, N=22$ sites with only one record per site used), while condition was unrelated to transplant survival ( $t=1.66, P=0.11, N=20$ sites). Mean condition at the time of sampling did not differ significantly for seedlings and transplants.

\section{VELB colonization}

VELB were recorded as present in $47 \%$ of the impact sites that led to the initiation of HCPs, based on records of recent VELB exit holes. This provides an index of the proportion of mitigation sites that should be occupied by VELB in order for there to be no net loss of sites containing VELB.

VELB appeared to most frequently enter mitigation sites inside of elderberry shrubs that were transplanted from the sites of impact: $28 \%$ of all sites, or $88 \%$ of sites to which shrubs potentially containing VELB were transplanted. The inference that VELB potentially colonized sites through transplanted shrubs comes from plants with VELB exit holes being transplanted. There is also a strong tendency for VELB to be present in the same shrubs in successive years-Talley et al. (2007) found that $70 \%$ of elderberry shrubs with new ( $\leq 1$ year old) holes along the American River Parkway (Sacramento, California) also contained old holes (1-10 year old holes) - hence it is likely that when shrubs containing VELB holes were transplanted, that the beetles were also transplanted. VELB also colonized sites of their own volition.

Shrubs at only 2 sites, one 3-year-old and one 10-yearold site, were colonized by VELB from sources other than transplantation (Fig. 3b). Hence, per site colonization rates in areas without the potential introduction of VELB by transplants were $2.3 \%$ for seedlings and $13.4 \%$ for transplants. Transplants were therefore colonized $5.8 \times$ more frequently than seedlings. The proportion of sites colonized did not appear to increase through time up to year 6 (Fig. 3); we did not attempt to evaluate this proportion for sites older than 6 years because of the very small number of sites available. Hence a total of $43 \%$ of sites contained VELB through introduction with transplants or colonization, representing a small net loss of local populations of VELB.

\section{Discussion}

Our results show that mitigation reporting and tracking of monitoring information is inadequate, at least for this one species at one office of the US FWS. We further 

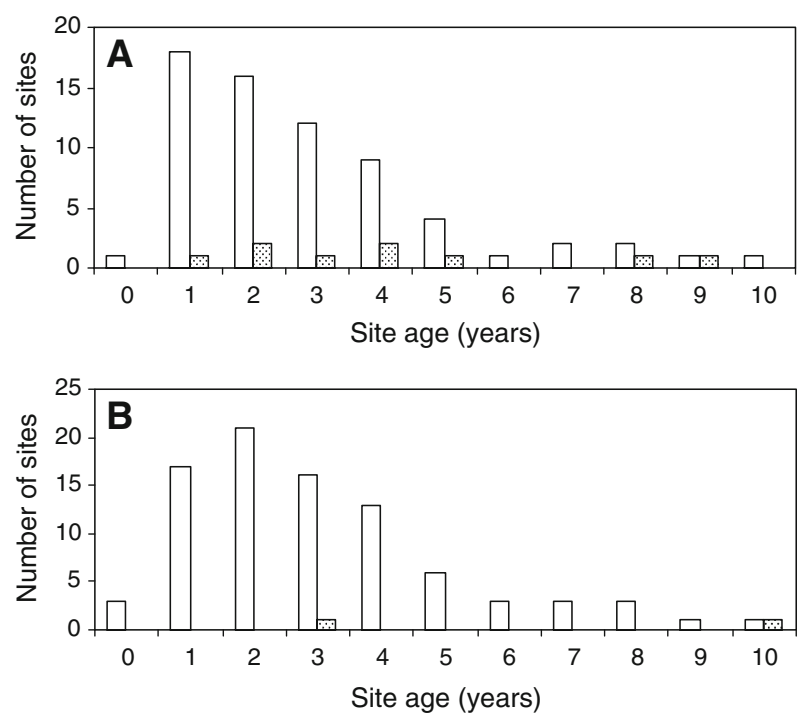

Fig. 3 Numbers of sites of different ages where VELB was present. a VELB presence in sites receiving transplants that contained VELB. The unfilled bars show the number of sites with transplanted shrubs, and stippled bars show numbers of sites with VELB present. In all of these cases VELB were potentially brought to the sites in the transplants (based on the presence of exit holes in shrubs at the time of transplanting). There were no cases in which VELB unequivocally colonized transplants without potentially being brought there in the transplants. b VELB colonization of seedlings for sites in which no shrubs containing VELB were brought to sites. Unfilled bars are numbers of sites with seedlings that could potentially have been colonized by VELB. Stippled bars show sites that were colonized by VELB in cases where we are certain that VELB did not arrive in transplanted shrubs

demonstrated the value of the data from mitigation reports for informing us about procedures that enhance the success of mitigation, and more generally for learning about the biology of an imperiled species.

\section{Reporting procedures}

It is striking how incomplete mitigation records for the VELB are, with only $36 \%$ of the expected reports being found in FWS files based on the presence of at least one report per site at FWS or CAS. These are approximate rates because they exclude sites where information on site initiation was missing and some reports may have been in use by FWS staff (and could not be located by these staff). It is quite likely that some reports were also lost by FWS given that records are not closely audited and evaluated. Reports submitted to the CAS library but not present at FWS indicate that an average of $63 \%$ of reports, were missing from FWS files but present at CAS. Hence we estimated that between 13 and $60 \%$ of reports have been lost by FWS or were unavailable for analysis if still present within the Sacramento FWS offices. There is a clear need for mitigation reporting to be more carefully tracked, for reports to be more systematically stored and enforcement of reporting to be checked. The problems identified likely result from a lack of funding and limited labor available to FWS for such activities. To further assess the extent of the problem, future work should also estimate the number of sites that were approved as mitigation sites and never planted. An online database and electronic archival system would be appropriate to ensure that mitigation data are submitted in a standardized format, to track reports and to ensure they are submitted. A consequence of this loss of information is that the tracking of cumulative impacts of mitigation by FWS (2007) is more a tracking of the range of likely values for cumulative impacts rather than an exact accounting - since total cumulative impacts depending on the success rate assumed for mitigation projects.

Mitigation reports were extremely inconsistent for some of the data reported (Table 1) -note that we chose to analyze on the more complete data fields. Examples of data that were note used in analyses because they were inadequate were information about elderberry growth in height (present in only $26 \%$ of reports) and growth in stem diameter (present in only $8 \%$ of reports). Elderberry condition was also infrequently recorded (Table 1). These variables are primarily indicators of mitigation sites state, and have not been found to be correlated with VELB presence or abundance (Talley 2007; Talley et al. 2007; Holyoak and Koch-Munz 2008). Therefore, although such data are useful, they are less useful than data on elderberry survival and size, which directly affect beetle abundance and presence. Even required things like number of elderberry planted or percent surviving were not always recorded (Table 1). Whether VELB had colonized sites was recorded in $81 \%$ of reports. The value of data in mitigation reports was often restricted by plantings from different years being reported together. The potential problems of doing this are illustrated by elderberry seedling survival, which is lower immediately following planting than in later years.

\section{Mitigation practices for VELB}

Mitigation efforts for the VELB were substantial (Table 2), with averages of 2.5 mitigation sites initiated per year, and planting of over 1,000 elderberry and 6,000 native plants per year. Efforts also varied substantially by county (Table 2). VELB were present at $47 \%$ of pre-impact sites, compared with $43 \%$ of mitigation sites. This potentially represents a slight net reduction in the number of sites with VELB present, but should be interpreted with caution because there is no standardization of the sampling effort for mitigation and impacted natural sites. We could not assess whether the total number of individual beetles has 
changed because of mitigation. Based on the planting of shrubs at ratios of two or more shrubs planted for each one destroyed and the mean shrub survival rates (Fig. 2), it is likely that there is a net gain in the number of elderberry shrubs from mitigation but quality of shrubs is unknown; this estimate does not, however, include sites for which mitigation information was missing entirely.

The rate of mitigation sites containing VELB belies the low rate of natural colonization of mitigation sites by VELB. VELB most frequently entered mitigation sites inside of elderberry shrubs transplanted from the sites of impact ( $28 \%$ of all sites, or $88 \%$ of sites to which shrubs containing VELB were transplanted). Only $16 \%$ of sites were colonized by VELB under their own volition. Given that it takes $\sim 7$ years for shrubs to have multiple stems of a sufficient size to support VELB and that monitoring only proceeds for 10-15 years, this is a small time for VELB to find and use elderberry shrubs. It is therefore not surprising that observed colonization rates by VELB were low (Fig. 3). There is a need to revisit older sites and ascertain whether VELB colonized, and for monitoring to be conducted for longer than 10 years. When VELB colonized sites they also used transplants (which lacked exit holes at the time of transplanting) $5.8 \times$ more frequently than seedlings. Hence transplants were disproportionately valuable for propagating VELB populations, because they often contained VELB at the time of transplanting, and they were sufficiently large at the time of transplanting to immediately provide VELB habitat.

Two suggestions arise from these findings. First, if elderberry is in an impact zone, the shrubs should be transplanted rather than sacrificed, especially when they may contain VELB. Second, it might be beneficial to transplant shrubs to older mitigation sites where seedlings have grown to suitable sizes for the VELB, so that beetles are not reliant solely on transplanted shrubs for their survival. The movement of transplants with VELB should be limited to within watersheds to avoid disrupting potential genetic population structure (based on metapopulations identified by Collinge et al. 2001).

It is our expectation that many other imperiled species would benefit from an assessment of mitigation data, which are publicly available. The US Endangered Species Act is by no means the only case in the world in which mitigation in some form is regularly performed to compensate for unavoidable losses to the habitat of imperiled species. For instance, New (2009) discusses the VELB and two other examples of habitat offsets which are assumed to compensate for habitat losses. Given that analogous regulatory and mitigation procedures are in place in other parts of the World it behooves conservation ecologists and policy makers to examine the efficacy of habitat offset processes.
Acknowledgments We wish to thank the employees of the Sacramento Office of FWS, especially David Wright (former employee) and Chris Nagano, for their comments on this work and help locating reports. Data collection efforts were aided by Molly Koch, Denise Piechnik and Tasila Banda-Sakala (UC-Davis). Funding for this project was provided by NFWF (Grant number 2003-0244-000), SAFCA, Sacramento County Parks, Sacramento County DERA, American River Flood Control District, PG\&E, SMUD, SRCSD, WAPA, California DWR and Reclamation Board, FHWA, and the City of Sacramento. We are especially grateful to Peter Buck and Tim Washburn (SAFCA) for their insightful orchestration of this productive multiagency collaboration. This project also benefited for Laura Svendsgaard's grant writing skills. We thank T. R. New and two anonymous referees for helpful comments. SEW was partly funded by the UC-Davis undergraduate grants program, and TST by UC-Davis Block Grant and an NSF IGERT grant.

Open Access This article is distributed under the terms of the Creative Commons Attribution Noncommercial License which permits any noncommercial use, distribution, and reproduction in any medium, provided the original author(s) and source are credited.

\section{References}

Allen WH (1994) Reintroduction of endangered plants-biologists worry that mitigation may be considered an easy option in the political and legal frameworks of conservation. Bioscience 44:65-68. doi:10.2307/1312203

Barr CB (1991) The distribution, habitat and status of the Valley elderberry longhorn beetle Desmocerus californicus dimorphus fisher (Insecta: Coleoptera: Cerambycidae). Report to US Fish and Wildlife Service, Sacramento

Bingham BB, Noon BR (1997) Mitigation of habitat "take": application to habitat conservation planning. Conserv Biol 11:127-139. doi:10.1046/j.1523-1739.1997.95331.x

Bonnie R (1999) Endangered species mitigation banking: promoting recovery through habitat conservation planning under the Endangered Species Act. Sci Total Environ 240:11-19. doi: 10.1016/S0048-9697(99)00315-0

Collinge SK, Holyoak M, Barr CB, Marty JT (2001) Riparian habitat fragmentation and population persistence of the threatened valley elderberry longhorn beetle in central California. Biol Conserv 100:103-113. doi:10.1016/S0006-3207(00)00211-1

Committee on Mitigating Wetland Losses, Board on Environmental Studies and Toxicology, Water Science and Technology Board, Division on Earth and Life Studies, National Research Council (2001) Compensating for wetland losses under the clean water act. National Academy Press, Washington, DC

Darlington RB (1990) Regression and linear models. McGraw-Hill, New York, p 480

Endangered Species Act (1973) Pub. L. 93-205, 81 Stat. 884, Dec. 28,1973

Fish and Wildlife Service (1980) Listing the Valley elderberry longhorn beetle as a threatened species with critical habitat. Fed Regist 45:52803

Fish and Wildlife Service (1981) Final rule: endangered and threatened wildlife and plants; final redefinition of harm. Fed Regist 46:54748

Fish and Wildlife Service (1984) Valley elderberry longhorn beetle recovery plan. US Fish and Wildlife Service, Portland

Fish and Wildlife Service (1988) Conservation guidelines for the Valley elderberry longhorn beetle. US Fish and Wildlife Service, Portland 
Fish and Wildlife Service (1994) Conservation guidelines for the Valley elderberry longhorn beetle, updated. US Fish and Wildlife Service, Portland

Fish and Wildlife Service (1996) Conservation guidelines for the Valley elderberry longhorn beetle, updated. US Fish and Wildlife Service, Portland

Fish and Wildlife Service (1999) Conservation guidelines for the Valley elderberry longhorn beetle, updated. US Fish and Wildlife Service, Portland. http://sacramento.fws.gov/es/documents/velb_ conservation.htm

Fish and Wildlife Service (2007) US Fish and Wildlife Service's response to AIBS/NCEAS's study: using science in habitat conservation plans. http://www.fws.gov/Endangered/hcp/response.htm

Fish and Wildlife Service, National Marine Fisheries Service (1998) Sect. 7 consultation handbook. http://www.fws.gov/endangered/ consultations/s7hndbk/s7hndbk.htm

Harding EK, Crone EE, Elderd BD et al (2001) The scientific foundations of habitat conservation plans: a quantitative assessment. Conserv Biol 15:488-500. doi:10.1046/j.1523-1739.2001. 015002488.x

Holyoak M, Koch-Munz M (2008) The effects of site conditions and mitigation practices on success of establishing the Valley elderberry longhorn beetle and its host plant blue elderberry. Environ Manag 42:444-457. doi:10.1007/s00267-008-9113-7

Huxel GR (2000) The effect of the Argentine ant on the threatened valley elderberry longhorn beetle. Biol Invasions 2:81-85. doi: 10.1023/A:1010015722996

Kareiva P, Andelman S, Doak D, Elderd B, Groom M, Hoekstra J, Hood L, James F, Lamoreux J, LeBuhn G, McCulloch C, Regetz J, Savage L, Ruckelshaus M, Skelly D, Wilbur H, Zamudio K, NCEAS Habitat Conservation Plan Working Group (1999) Using science in habitat conservation plans. AIBS, Washington DC

Katibah EE, Dummer KJ, Nedeff NE (1984) Current condition of riparian resources in the Central Valley of California. In: Warner RE, Hendrix KM (eds) California riparian systems: ecology, conservation, and productive management. University of California Press, Berkeley, pp 314-321
Koch-Munz M, Holyoak M (2008) An evaluation of the effects of soil characteristics on mitigation and restoration involving blue elderberry, Sambucus mexicana. Environ Manag 42:49-65. doi: 10.1007/s00267-008-9074-x

Linsley EG, Chemsak JA (1972) Cerambycidae of North America. Part VI, No. 1. Taxonomy and classification of the subfamily lepturinae. Univ Calif Publ Entomol 69:1-138

New T (2009) Habitat offsets for insect species conservation: practicality or placebo? J Insect Conserv 13:139-141. doi: 10.1007/s10841-008-9196-8

Noss RF, O'Connell M, Murphy D (1997) The science of conservation planning. Island Press, Washington, D.C., p 246

Smallwood KS, Beyea J, Morrison ML (1999) Using the best scientific data for endangered species conservation. Environ Manag 24:421-435. doi:10.1007/s002679900244

Smith F (1980) Riparian forests in California: their ecology and conservation: a symposium. In: Sands A (ed) Division of agricultural sciences, University of California, Berkeley, pp 1-2

Talley TS (2007) Which spatial heterogeneity framework? Consequences for conclusions about patchy population distributions. Ecology 88:1476-1489. doi:10.1890/06-0555

Talley TS, Wright D, Holyoak M (2006) Assistance with the 5-year review of the valley elderberry longhorn beetle (Desmocerus californicus dimorphus). United States Fish and Wildlife Service, Sacramento. http://www.fws.gov/sacramento/es/documents/VELB_5yr_review_ Talley_etal.pdf

Talley TS, Fleishman E, Holyoak M et al (2007) Rethinking a rarespecies conservation strategy in an urban landscape: the case of the valley elderberry longhorn beetle. Biol Conserv 135:21-32. doi:10.1016/j.biocon.2006.09.022

US Census Bureau (2005) QuickFacts. http://quickfacts.census.gov/

Watchman LH, Groom M, Perrine JD (2001) Science and uncertainty in habitat conservation planning. Am Sci 89:351

Wilhere GF (2002) Adaptive management in habitat conservation plans. Conserv Biol 16:20-29. doi:10.1046/j.1523-1739.2002. 00350.x 